\title{
MATERNAL AND PERINATAL OUTCOME IN PREECLAMPSIA AT A TERTIARY CARE CENTRE VIJAYAWADA, ANDHRA PRADESH, INDIA
}

\author{
Potharaju Jayanthi', Prasad Usha
}

${ }_{1}^{1}$ Associate Professor, Department of Obstetrics and Gynaecology, Siddhartha Medical College, Vijayawada. ${ }^{2}$ Associate Professor, Department of Obstetrics and Gynaecology, Siddhartha Medical College, Vijayawada.

\begin{tabular}{l}
\hline ABSTRACT \\
BACKGROUND \\
mateeclampsia is one of the important causes of maternal and perinatal mortality in India. This study was conducted to evaluate the \\
and perinatal outcome of preeclampsia and its complications.
\end{tabular}

\section{MATERIALS AND METHODS}

A descriptive study was conducted on 100 consecutive women admitted with preeclampsia and its complication to Government General Hospital Vijayawada, Andhra Pradesh, from May 2017 to September 2017. The emergency and elective admissions were followed for mode of delivery. Maternal and perinatal outcomes were followed till discharge.

\section{RESULTS}

In the present study, 100 consecutive admissions with preeclampsia and its complications at different gestational ages were studied. In total 100 cases $39 \%$ were referred from rural areas with a referral slip associated with complications, 57\% patients were delivered by abdominal route and $43 \%$ were delivered vaginally. Overall, perinatal deaths were 15.

\section{CONCLUSION}

Preeclampsia is an important disorder in obstetrics. Early identification and prompt diagnosis and treatment decreases maternal and perinatal mortality and morbidity.

\section{KEYWORDS}

Preeclampsia, Hypertension, Mortality.

HOW TO CITE THIS ARTICLE: Jayanthi P, Usha P. Maternal and perinatal outcome in preeclampsia at a tertiary care centre Vijayawada, Andhra Pradesh, India. J. Evolution Med. Dent. Sci. 2017;6(92):6598-6601, DOI: 10.14260/jemds/2017/1430

\section{BACKGROUND}

Preeclampsia is a multisystem disorder characterised by hypertension, new-onset proteinuria which develops after 20 weeks.1,2 New-onset thrombocytopenia, impaired liver function, renal insufficiency, pulmonary oedema, visual or cerebral disturbances also can be diagnostic even without proteinuria. $^{2}$ Incidence is high in developing countries, especially low socio-economic status, rural areas.3,4 Preeclampsia is reported as leading cause of maternal mortality. It is estimated that $7 \%$ maternal mortality is associated with hypertensive disorders, particularly eclampsia. Preeclampsia is associated with 5 -fold in case of perinatal mortality. 5

\section{Aims and Objectives}

The aim of present study is to evaluate the maternal and perinatal outcome of preeclampsia in patients admitted at Government General Hospital, Vijayawada- a tertiary care centre in Andhra Pradesh, South India.

'Financial or Other Competing Interest': None.

Submission 07-11-2017, Peer Review 20-11-2017,

Acceptance 22-11-2017, Published 04-12-2017.

Corresponding Author:

Dr. Potharaju Jayanthi,

Plot No. 115, $2^{\text {nd }}$ Lane,

NGGO Colony,

Venugopala Nagar,

Guntur, Andhra Pradesh.

E-mail: jayanthipotharaju1969@gmail.com

DOI: $10.14260 /$ jemds $/ 2017 / 1430$

\section{(c) (1) $(9)$}

\section{MATERIALS AND METHODS}

\section{Study Design}

A Descriptive Study.

The study was conducted in Government General Hospital, Vijayawada, Andhra Pradesh, a tertiary care centre with 6000 deliveries per annum. The study was conducted in the year 2017 from the month of May. Inclusion criteria was total 100 consecutive cases, patients with preeclampsia. This includes all antenatal ward admission and emergency admissions.

On admission detailed history was taken, general and obstetric examination was done. Investigation was sent. 74\% of cases were admitted in labour room; $26 \%$ were admitted in the ward. All complications at the time of admission were noted. After the investigations mode of delivery, plan of delivery, maternal and perinatal outcome was studied. All cases were followed till discharge.

\section{RESULTS}

The result of present study was tabulated and analysed.

\begin{tabular}{|c|c|c|}
\hline Distribution of Cases & $\mathbf{N = 1 0 0}$ & $\mathbf{\%}$ \\
\hline Booked & 49 & $49 \%$ \\
\hline Unbooked & 51 & $51 \%$ \\
\hline Total & 100 & $100 \%$ \\
\hline \multicolumn{2}{|r|}{ Table 1. Distribution of Cases } \\
\hline
\end{tabular}

In total 100 cases of preeclampsia there is almost equal distribution of booked and unbooked cases, $49 \%$ booked and 51\% unbooked cases; 39 cases had check-ups at outside 
hospital including PHC/ CHC and admitted along with referral slip from rural area. Remaining $12 \%$ of patients have checkup at private clinics and came directly to labour room due to financial reasons. This shows that even though $51 \%$ of cases were unbooked to GGH Vijayawada, all pregnant women had check-ups at other centres.

\begin{tabular}{|c|c|c|}
\hline Cause of Referral & $(n=39)$ & $\%$ \\
\hline Severe preeclampsia & 13 & $33.3 \%$ \\
\hline Eclampsia & 11 & $28.2 \%$ \\
\hline IUD (F) & 9 & $23.07 \%$ \\
\hline Abruption & 6 & $15.38 \%$ \\
\hline Total & 39 & \\
\hline
\end{tabular}

All the referral cases are from rural areas, remaining 12 cases are admitted to emergency ward with labour pains; $13 \%$ of cases were referred in view of preeclampsia, $11 \%$ were referred in view of eclampsia, $9 \%$ patients were referred in view of intrauterine foetal death; $6 \%$ of cases were referred in view of abruption.

In present study, $54 \%$ are from rural areas and $46 \%$ from urban areas. There is almost equal distribution of patients from rural and urban areas.

\begin{tabular}{|c|c|c|}
\hline \multicolumn{2}{|c|}{$\mathbf{n = 1 0 0}$} & $\mathbf{\%}$ \\
\hline$<20$ yrs. & 22 & $22 \%$ \\
\hline $20-25$ yrs. & 60 & $60 \%$ \\
\hline $25-30$ yrs. & 10 & $10 \%$ \\
\hline $30-35$ yrs. & 6 & $6 \%$ \\
\hline$>35$ yrs. & 2 & $2 \%$ \\
\hline Total & 100 & \\
\hline Table 2. Age Wise Distribution of Cases \\
\hline
\end{tabular}

\begin{tabular}{|c|c|c|}
\hline & $\mathbf{N = 1 0 0}$ & $\mathbf{\%}$ \\
\hline Primi & 60 & $60 \%$ \\
\hline $\mathrm{G}_{2} \mathrm{~A}_{1}$ & 7 & $7 \%$ \\
\hline $\mathrm{G}_{2} \mathrm{P}_{1} \mathrm{~L}_{1}$ & 25 & $25 \%$ \\
\hline $\mathrm{G}_{3}$ & 5 & $5 \%$ \\
\hline $\mathrm{G}_{4}$ & 2 & $2 \%$ \\
\hline $\mathrm{G}_{5}$ & 1 & $1 \%$ \\
\hline \multicolumn{2}{|c|}{ Table 3. Parity Wise Distribution of Cases } \\
\hline \multicolumn{2}{|c|}{}
\end{tabular}

In the present study $60 \%$ were primi gravidae, $7 \%$ were second gravid with one abortion, $25 \%$ were second gravid with previous live child, $5 \%$ were gravid 3 . About $60 \%$ of pregnant women were in the age group of 20 to 25 years; $22 \%$ contribution by pregnant women of less than 20 years, $10 \%$ of pregnant patients were in the age group of 25 to 30 years. Only 2 patients were above 35 years. This study shows that preeclampsia is common in primi gravidae and young pregnant women.

\begin{tabular}{|c|c|}
\hline$<28$ weeks & 5 \\
\hline 28-32 weeks & 15 \\
\hline 32-36 weeks & 15 \\
\hline$>36$ weeks & 63 \\
\hline$>40$ & 2 \\
\hline Total & 100 \\
\hline
\end{tabular}

Elective admissions- 26, Emergency-Unbooked- 51, Booked- 23.
In the present study $63 \%$ were admitted at 36 weeks, $15 \%$ got admitted between 32 - 36 weeks and $15 \%$ between 28 - 32 weeks; $74 \%$ of admissions were in emergency ward and $26 \%$ were admitted in antenatal ward.

\begin{tabular}{|c|c|}
\hline Eclampsia & 11 \\
\hline Abruption & 6 \\
\hline GDM & 4 \\
\hline Twins & 4 \\
\hline Oligohydramnios & 2 \\
\hline Hypothyroid & 1 \\
\hline Bronchial asthma & 1 \\
\hline Fever & 1 \\
\hline Low platelet count & 1 \\
\hline
\end{tabular}

Table 5. Maternal Complications at Time of Admission

In present study 11 patients were admitted with eclampsia and 6 pregnant women were admitted with abruption. These two i.e. eclampsia and abruption contributed to most of the complications i.e. $66 \%$. Because our hospital is a tertiary care centre, we admit complicated cases; 4 patients were joined in view of GDM; 2 patients got admission in view of oligohydramnios; 4 cases of twins, hypothyroid, asthma, fever, low platelet count patients of one case each. Present study shows that in addition to preeclampsia, other medical disorders also can equally complicate the pregnant women.

\begin{tabular}{|c|c|}
\hline$<24$ hrs. & 42 \\
\hline $24-72$ hrs. & 41 \\
\hline 3 to 5 days & 11 \\
\hline 5 to 10 days & 1 \\
\hline >10 days & 5 \\
\hline Table 6. Admission-Delivery Interval \\
\hline
\end{tabular}

In present study, $42 \%$ delivered within 24 hours of admission; $41 \%$ of pregnant women delivered within 24 to 72 hours. This is because $51 \%$ cases are unbooked and admitted in labour room and needed early termination to prevent complications; $11 \%$ women delivered between 3 to 5 days, remaining 6 patients were admitted in antenatal ward and put on conservative management. Pregnancy continued till lung maturity. Termination was done after 37 weeks.

\begin{tabular}{|c|c|}
\hline \multicolumn{2}{|c|}{} \\
\hline Preterm & 30 \\
\hline IUGR & 12 \\
\hline IUFD & 11 \\
\hline Still birth & 1 \\
\hline Neonatal death & 3 \\
\hline Table 7. Perinatal Complications \\
\hline
\end{tabular}

Among the foetal complications, preterm is the emerging problem. In the present study, $30 \%$ of patients delivered prematurely. This include both spontaneous and induced labours. Most of the cases needed induction because of preeclampsia. With severe features and other complications, 11 patients were admitted with IUFD and one still birth. Iatrogenic prematurity is an important issue, but it is necessary to save the mother most often. 


\begin{tabular}{|c|c|}
\hline$<28$ weeks & 3 \\
\hline Preterm vaginal & 19 \\
\hline Preterm emergency LSCS & 11 \\
\hline Hysterotomy & 2 \\
\hline Normal delivery & 17 \\
\hline Outlet forceps & 4 \\
\hline Elective LSCS & 5 \\
\hline Emergency of LSCS & 39 \\
\hline Total & 100 \\
\hline Table 8. Mode of Delivery \\
\hline
\end{tabular}

In our series, total number of caesarean sections including hysterotomy were $57 \%$; $5 \%$ were elective LSCS. Remaining 52\% LSCS were done in emergency; $56 \%$ of caesarean sections were done under spinal anaesthesia. Only one case of low platelet count was taken up under general anaesthesia. No anaesthesia complications were reported.

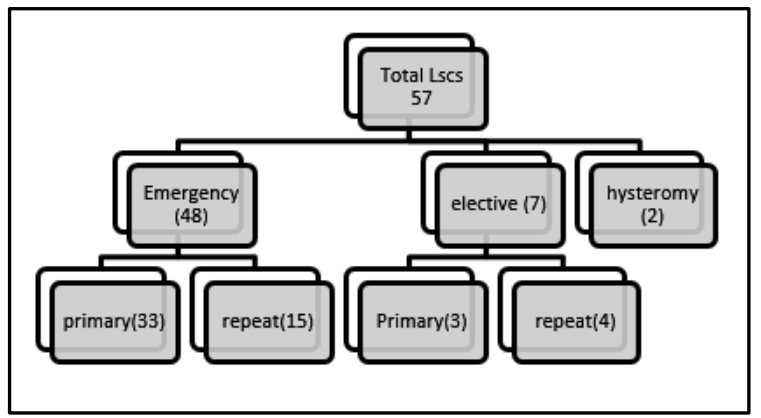

\begin{tabular}{|lcl|}
\hline Total Primary LSCS-36 & $\mathbf{n}=\mathbf{3 6}$ & $\%$ \\
Indications: Failed induction & 12 & $33.33 \%$ \\
CPD & 11 & $30.5 \%$ \\
Fetal distress & 7 & $19.41 \%$ \\
Oligohydramnios & 4 & $11 \%$ \\
Mal presentation & 2 & $5 \%$ \\
\hline
\end{tabular}

Primary caesarean sections contributed to $63 \%$ of total. Failed induction and CPD were most important indications for caesarean sections; $33 \%$ of primary LSCS were done because of failed induction. CPD contributed to $30.5 \%$ of primary LSCS; $19.41 \%$ caesarean sections were due to foetal distress. Oligohydramnios and malpresentations contributed to $11 \%$ and $5 \%$ consecutively.

\section{Perinatal Outcome}

Total number of live births 88 ( 3 neonatal deaths in NICU)

Macerated still birth $\quad 11$

Fresh still birth

1

Take home babies was $85 \%$, perinatal loss of about $15 / 100$. Total 88 live births at the time of delivery. Total 28 babies were admitted in NICU (Table 12). One case of still birth due to meconium aspiration; 3 babies died in NICU after 3 days.

\begin{tabular}{|c|c|}
\hline$<500$ gms & 3 \\
\hline $500-1000$ gms & 6 \\
\hline $1 \mathrm{~kg}$ to $1.5 \mathrm{~kg}$ & 11 \\
\hline $1.5-2.5 \mathrm{~kg}$ & 30 \\
\hline $2.5-3.5 \mathrm{~kg}$ & 44 \\
\hline $3.5-4.0 \mathrm{~kg}$ & 3 \\
\hline$>4 \mathrm{~kg}$ & 3 \\
\hline$>5 \mathrm{~kg}$ & 1 \\
\hline \multicolumn{2}{|c|}{ Table 9. Birth Weights of Babies } \\
\hline
\end{tabular}

$44 \%$ of new born weighed between 2.5 and $3.5 \mathrm{kgs}$.

$30 \%$ of new born weighed between 1.5 and $2.5 \mathrm{kgs}$.

$20 \%$ of babies weighed less than $1 \mathrm{~kg}$.

4 babies weighed more than $4 \mathrm{~kg}$. All cases were GDM patients.

Total 28 babies were admitted in NICU; 14 babies weighed less than $1.5 \mathrm{~kg}$; 10 babies weighed between 1.5 to $2.5 \mathrm{kgs}$ and 4 babies more than $2.5 \mathrm{~kg}$ were admitted in NICU. Total 3 babies died in NICU.

\section{RESULTS}

In total 100 cases of present study, all mothers were discharged in good condition; $57 \%$ caesarean section rate, $15 \%$ of babies lost. High perinatal deaths, because the study is from tertiary care hospital. Macerated still birth contributed to 11 cases, 1 fresh still birth and 3 neonatal deaths.

\section{DISCUSSION}

Hypertensive disorders are amongst the most common medical complications affecting $6 \%$ to $8 \%$ of all pregnancies, ${ }^{6}$ approximately $30 \%$ of hypertensive cases are due to chronic hypertension. Remaining $70 \%$ are caused by gestational hypertension and preeclampsia. Preeclampsia is a disorder unique to human pregnancy.

It is important to understand the disease process. There is high impact of hypertensive disorders and their complications on pregnant population. The disease remains as a major cause of maternal and perinatal mortality and morbidity, not only in India but also worldwide. If preeclampsia was not detected early and treated, it can lead to catastrophic complications.

In the present study, there is almost equal distribution of booked and unbooked cases, 49\% and 51\% respectively. In unbooked cases 39 cases had check-ups at PHC and CHC and referred with referral slip, because our hospital is a tertiary hospital. All complications of preeclampsia were referred in cases; $60 \%$ patients are in the age group of $20-25 \mathrm{yrs}$. This is almost equal to the study of Manjusha, where they quoted the mean age group of 18 - 22 years. In their study, $49.15 \%$ of patients belonged to the age group between 18 and 22.7

In present study both rural and urban population were equally affected, $54 \%$ and $46 \%$ respectively. Study from Septa Agarwal and Gagandeep K Walia quoted that on average in India $56.2 \%$ rural and $53.8 \%$ urban population were affected by preeslampsia. 833 rural population in Haryana and $87 \%$ rural population in Tripura were affected with preeclampsia; 83\% patients delivered within 72 hours showing that timely termination save the mother. In present study $39 \%$ of complications were referred from rural areas. Severe preeclampsia, eclampsia and abruption were the important maternal complications and these were the major causes for referral. Macerated still birth was another major cause for referral. 33\% of cases were referred in view of severe preeclampsia. $28 \%$ of referrals were because of eclampsia and $23.07 \%$ of referrals were due to abruption.

In our series, $57 \%$ were delivered by abdominal route. This is almost similar to other studies (Pacher J and Brixe Lehner). Their study showed that most frequent mode of delivery in preeclampsia is caesarean section. ${ }^{9}$ In study of CD Mushilone and J Moodley, they quoted that elective caesarean section contributed to better perinatal outcome.10 In our 
hospital in induced cases, early decision for caesarean section was taken up if needed. Hence, $57 \%$ caesarean section rate. With 55 live babies, 2 macerated still birth babies. In present study total perinatal loss was $15 \%$, which was almost equal to other studies.

\section{CONCLUSION}

Preeclampsia is an important disorder in obstetrics. Early identification and referral to tertiary care hospital is necessary to prevent complications and to reduce maternal and perinatal mortality, especially in India. Better training of ASHA workers and staff nurses in early identification of preeclampsia and its complications can minimise the problems in rural areas.

\section{REFERENCES}

[1] Duley L. Pre-eclampsia and the hypertensive disorder of pregnancy. Br Med Bull 2003;67:161-76.

[2] American College of Obstetrics and Gynaecology. Hypertension in pregnancy. Report of the American college of obstetricians and gynecologists' task force on hypertension in pregnancy. Obstet Gynaecol 2013;122(5):1122-31.

[3] Onwuhafua PI, Onwuhafua A, Adze J, et al. Eclampsia in kaduna state of nigeria--a proposal for a better outcome. J Med 2001;10(2):81-4.
[4] Chattopadhyay S, Das A, Pahari S. Fetometernal outcome in seven preeclampsia women undergoing emergency cesarean section under either general or spinal anesthesia. Journal of Pregnancy 2014;2014:10.

[5] The WHO publication of ICD-10 to deaths during pregnancy child birth and puerperium. $1 \mathrm{CD}, \mathrm{m} . \mathrm{m}$. 2013.

[6] Report of national high blood pressure education program working group on high blood pressure in pregnancy. Am J Obstet Gynecol 2000;183(1):S1-22.

[7] Sajith M, Nimbargi V, Modi A, et al. Incidence of pregnancy induced hypertension and prescription pattern of antihypertensive drugs in pregnancy. Int J Pharm Sci Res 2014;5(4):163-70.

[8] Agrawal S, Walia GK. Prevalence and risk factors for pre-eclampsia in Indian women a national cross sectional study. J Womens Health 2014;3(6):2-9.

[9] Pacher J, Brix E, Lehner R. The mode of delivery in patients with preeclampsia at term subjected to elective or emergency caesarean section. Arch Gynecol Obslet 2014;289(2):263-7.

[10] Mashiloane CD, Moodley J. Induction or caesarean section for preterm pre-eclampsia? J Obstet Gynaecol 2002;22(4):353-6. 